\title{
Acceleration of type 1 diabetes mellitus in proinsulin 2-deficient NOD mice
}

\author{
Karine Thébault-Baumont, ${ }^{1}$ Danielle Dubois-Laforgue, ${ }^{1}$ Patricia Krief, ${ }^{1}$ Jean-Paul Briand, ${ }^{2}$ \\ Philippe Halbout, ${ }^{1}$ Karine Vallon-Geoffroy, ${ }^{1}$ Joëlle Morin, ${ }^{1}$ Véronique Laloux, ${ }^{1}$ \\ Agnès Lehuen, ${ }^{1}$ Jean-Claude Carel, ${ }^{1}$ Jacques Jami, ${ }^{3}$ Sylviane Muller, ${ }^{2}$ \\ and Christian Boitard ${ }^{1}$
${ }^{1}$ Institut National de la Santé et de la Recherche Médicale (INSERM) U561, Hôpital Cochin-Saint Vincent de Paul, Paris, France
${ }^{2}$ Centre National de la Recherche Scientifique Unité Propre de Recherche 9021, Institut de Biologie et Génétique Moléculaire, Strasbourg, France
${ }^{3}$ INSERM U567, Hôpital Cochin-Saint Vincent de Paul, Paris, France

\begin{abstract}
Accumulating evidence favors a role for proinsulin as a key autoantigen in diabetes. In the mouse, two proinsulin isoforms coexist. Most studies point to proinsulin 2 as the major isoform recognized by $T$ cells in the NOD mouse. We studied mice in which a null proinsulin 2 mutation was transferred from proinsulin 2-deficient 129 mice onto the NOD background along with 16 genetic markers (including $\mathrm{I}-\mathrm{A}^{\mathrm{g} 7} \mathrm{MHC}$ molecule) associated with diabetes. Intercross mice from the fourth backcross generation showed that proinsulin $2^{-/-}$mice develop accelerated insulitis and diabetes. The high prevalence of anti-insulin autoantibodies in proinsulin $2^{-/-}$mice indicates that diabetes acceleration relates to altered recognition of proinsulin. The prevalence of anti-glutamic acid decarboxylase autoantibodies and of sialitis is not increased in proinsulin $2^{-/-}$mice. We give evidence that proinsulin 2 expression leads to silencing of $\mathrm{T}$ cells specific for an epitope shared by proinsulin 1 and proinsulin 2 . In the human, alleles located in the VNTR region flanking the insulin gene control $\beta$ cell response to glucose and proinsulin expression in the thymus and are key determinants of diabetes susceptibility. Proinsulin $2^{-/-}$NOD mice provide a model to study the role of thymic expression of insulin in susceptibility to diabetes.

This article was published online in advance of the print edition. The date of publication is available

from the JCI website, http://www.jci.org. J. Clin. Invest. 111:851-857 (2003). doi:10.1172/JCI200316584.
\end{abstract}

\section{Introduction}

Several autoantigens are targets of autoantibodies and $\mathrm{T}$ cells in type 1 diabetes. These include insulin, glutamic acid decarboxylase (GAD) 65 and 67, tyrosine phosphatase-like IA-2, heat shock protein 60 , and other poorly defined antigens $(1,2)$. Accumulating evidence favors a role of proinsulin as a key autoantigen. In the human, insulin and proinsulin are common targets of autoantibodies (3-5) and T cells in prediabetic individuals (6). Anti-insulin antibodies are the first autoantibodies detected in children at risk for diabetes (7) and carry a high positive predictive value for diabetes in siblings of type 1 diabetes patients. In the mouse, T cell clones specific for insulin accelerate diabetes when injected in the NOD mouse $(8,9)$. Protection from diabetes is obtained by injecting insulin, insulin $B$ chain (10), or insulin $2 \mathrm{~B}$ chain peptide $9-23$ in prediabetic

Received for publication August 5, 2002, and accepted in revised form January 15, 2003.

Address correspondence to: Christian Boitard, INSERM U561, Hôpital Saint Vincent de Paul, 82 Avenue Denfert Rochereau, 75014 Paris, France. Phone: 33-0-1-40-48-82-49;

Fax: 33-0-1-40-48-83-52; E-mail: boitard@cochin.inserm.fr.

Conflict of interest: The authors have declared that no conflict of interest exists.

Nonstandard abbreviations used: glutamic acid decarboxylase (GAD); backcross (BC); anti-insulin autoantibody (IAA). mice $(11,12)$. In addition, a $\mathrm{K}^{\mathrm{d}}$-restricted $\mathrm{CD}^{+} \mathrm{T}$ cell clone that transfers diabetes into naive mice has been shown to recognize insulin B chain peptide 15-23 (13).

Proinsulin, a major $\beta$ cell protein, is the only autoantigen that is almost exclusively expressed in $\beta$ cells. In the human, alleles in the VNTR region flanking the insulin gene control both the $\beta$ cell response to glucose and the expression of proinsulin in the thymus and are important determinants of genetic susceptibility to diabetes (14-16). In the mouse, there is no VNTR in the $5^{\prime}$ region flanking the insulin gene, but two proinsulin isoforms encoded by genes located on chromosomes 7 and 19 coexist (17). They differ by two amino acid residues in $B$ chain, three amino acid residues in $C$ peptide, and several amino acid residues in the leader sequence. They also share most of their primary structure, especially in the A chain sequence. Proinsulin 2 is expressed in both $\beta$ cells and the thymus, while expression of proinsulin 1 in the thymus has been debated (18-21).

To evaluate the role of proinsulin 2 in diabetes, we introduced a null mutation for the proinsulin 2 gene by crossing proinsulin $2^{-/-} 129$ mice with NOD mice. Breeders were selected for carrying 16 genetic markers (including $I-A^{g 7} M H C$ gene) associated with diabetes in the NOD model. Proinsulin $2^{-/-}$mice generated by intercrossing backcross 4 (BC4) mice developed highly accelerated insulitis and diabetes. 


\section{Methods}

Animals. Proinsulin 2-deficient 129 mice (17) and NOD mice were bred in our facilities under specific pathogen-free conditions. The prevalence of diabetes in our NOD colony reaches $30 \%$ in males and $75 \%$ in females by 6 months of age. Throughout this article, proinsulin $2^{-/-}$NOD homozygote mice are denoted as Ins $2^{-/-}$, proinsulin $2^{+/-}$NOD heterozygote mice as Ins $2^{+/-}$, and proinsulin $2^{+/+}$NOD heterozygote mice as Ins $2^{+/+}$.

Development of proinsulin 2-deficient NOD mice. A proinsulin 2-null allele obtained by deletion of most of the proinsulin coding sequence and insertion of Lac $Z$ and neomycin resistance $(\mathrm{Neo})$ genes was introduced into the NOD inbred background from an original chimeric stock (17) sharing a mixed 129 and C57BL/6 genome. Proinsulin 2-deficient 129 mice were backcrossed to NOD mice for four generations. Heterozygote carriers of the proinsulin 2-deficient allele were genotyped for the Neo and LacZ genes using previously described primers (5'-GTG TTC CGG CTG TCA GCG CA-3' and 5' GTC CTG ATA GCG GTC CGC CA-3' for Neo; $5^{\prime}$-CCA GCG ACC AGA TGA TCA CA-3' and ACG GCA CGC TGA TTG AAG CA-3' for LacZ) and were used as breeders at each backcross generation. Mice from the second to the fourth backcross generations were genotyped for microsatellite markers linked to Idd loci (Idd1 to Idd16) as previously described (22). At BC4, Ins $2^{+/-}$mice shown to be homozygous for Idd1 to Idd16 NOD alleles were intercrossed. Ins $2^{-/-}$mice were distinguished from Ins $2^{+/-}$heterozygotes by amplification of the proinsulin 2 gene using $3^{\prime}$ and $5^{\prime}$ primers $\left(5^{\prime}\right.$-CAG TAG TTC TCC AGC TGG TA-3' and $5^{\prime}$-GGC TTC TTC TAC ACA CCC A-3') (17), providing a 675-bp fragment only in heterozygote mice. Since the proinsulin 2 gene is located on distal chromosome 7 at $64.5 \mathrm{cM}$, we tested markers located at $3.3 \mathrm{cM}$ (D7Mit191), $12.0 \mathrm{cM}$ (D7Mit308), $26.2 \mathrm{cM}$ (D7Mit232), $41.5 \mathrm{cM}$ (D7Mit253), and $64.5 \mathrm{cM}$ (D7Mit242), according to the Massachusetts Institute of Technology database.

Detection of proinsulin RNA in pancreas and thymus. RNAs were extracted from freshly collected thymus, kidney, and islets using guanidinium thiocyanate and treated with DNase before reverse transcription to avoid contamination with genomic DNA. Islets of Langerhans were isolated as previously described (23). Proinsulin transcripts were amplified using two pairs of primers, 5'-CAG CTC CAG TTG TGC CAC TTG TG-3' and 5'-CCA TCA GCA AGC AGG TTA TTG TTT C- $3^{\prime}$, that are specific for the proinsulin 2 gene and provide a 232-bp fragment. Assessment of diabetes, insulitis, and sialitis. Starting at 4 weeks of age, mice were monitored weekly for glycosuria using test strips. Blood glucose was measured (EuroFlash; Lifescan, Johnson and Johnson Co., Milpitas, California, USA) when glycosuria was detected. Mice were considered diabetic after two consecutive instances of glycemia over $300 \mathrm{mg} / \mathrm{dl}$. The onset of diabetes was dated from the first of the sequential glycemia measurements.

To score insulitis, pancreata were fixed in $4 \%$ formaldehyde solution, dehydrated, and embedded into paraffin; 5 - $\mu \mathrm{m}$ sections were stained with $\mathrm{H} \& \mathrm{E}$ and scored blindly for severity of insulitis as previously reported (24).

Sialitis was scored on tissue sections prepared as previously reported (24). Results were expressed as numbers of mononuclear cell infiltrates per 100 squares of serous tissue, or as surface of infiltrate divided by surface of serous tissue $\times 100$, and expressed as mean \pm SEM.

Insulinemia and glucose tolerance tests. Glucose tolerance tests were performed in 6-month-old wild-type and proinsulin 2 -deficient $129 / \mathrm{Sv}$ mice by intraperitoneal injection of D-glucose $(2 \mathrm{~g} / \mathrm{kg})$ after overnight fasting. Blood samples were collected from the retro-orbital sinus at 0, 60, and 120 minutes, and glucose levels were determined as previously indicated. Fasting insulinemia levels were determined using an RIA kit (Linco Research Inc., St. Charles, Missouri, USA).

Adoptive transfer experiments. Erythrocyte-depleted spleen cells $\left(2 \times 10^{7}\right.$ per recipient) were injected i.v. in 8 -week-old NOD-scid recipients. In the case of diabetic control donors, $10^{7}$ spleen cells were transferred.

Assay for anti-insulin autoantibodies. Anti-insulin autoantibodies (IAAs) were detected as previously described (5). Briefly, $5 \mu$ l of serum was incubated with or without human cold insulin and with ${ }^{125} \mathrm{I}$-insulin (Amersham Pharmacia Biotech Europe, Orsay, France). After a 3-day incubation at $4{ }^{\circ} \mathrm{C}, 50 \mu \mathrm{l}$ of protein A- and protein G-Sepharose (Amersham Pharmacia Biotech Europe) was added overnight at room temperature in a multiscreen 96-well filtration microplate (Millipore Corp., Bedford, Massachusetts, USA) precoated with buffer A (1\% BSA, $0.1 \%$ sodium azide, $0.15 \%$ Tween-20). After incubation and washing, $40 \mu \mathrm{l}$ of scintillation liquid MicroScint-20 (Packard Instrument Co., Meriden, Connecticut, USA) was added, and radioactivity was measured in the 96-well plate in a Top Count scintillation counter (Packard Instrument Co.). Results were calculated on the basis of the difference in cpm $(\Delta \mathrm{cpm})$ between the well without and the well with cold insulin and expressed as an index: index $=($ sample $\Delta \mathrm{cpm}-$ negative control $\Delta \mathrm{cpm}) /($ positive control $\Delta \mathrm{cpm}-$ negative control $\Delta \mathrm{cpm}) \times 100$. Positivity was defined from values obtained in normal strains as previously described (5) and set to 0.01 .

Autoantibodies to GAD. Autoantibodies to GAD were detected using ELISA (25). A GAD concentration of 10 $\mu \mathrm{g} / \mathrm{ml}$ in $0.1 \mathrm{M}$ carbonate buffer ( $\mathrm{pH}$ 9.6) was used to coat the plates. After blocking of the plates, diluted sera (1:5) were incubated overnight at $4{ }^{\circ} \mathrm{C}$, and alkaline phosphatase-conjugated polyclonal anti-murine IgG (Sigma-Aldrich, Saint Quentin Fallavier, France) was added. PNPP was used for detection.

Peptide synthesis. As described previously (26), the peptides were synthesized using Fmoc chemistry by the stepwise solid-phase methodology on a multichannel peptide synthesizer (27), and purified by reversed-phase HPLC (RP-HPLC) using a Perkin-Elmer preparative HPLC system (Perkin-Elmer, Courtaboeuf, France). The purity of each peptide was assessed by analytical RPHPLC on a System gold instrument (Beckman Coulter, 
Roissy, France). RP-HPLC was performed on a Nucleosil C18 5 - $\mu \mathrm{m}$ column $(150 \times 4.6 \mathrm{~mm})$ using a linear gradient of $0.1 \%$ trifluoroacetic acid in water and acetonitrile containing $0.08 \%$ trifluoroacetic acid at a flow rate of 1.2 $\mathrm{ml} / \mathrm{min}$. Integrity of each peptide was controlled by matrix-assisted laser desorption and ionization time-offlight (MALDI-TOF) on a Protein TOF mass spectrometer (Bruker SA, Wissembourg, France) (25). The peptide set was composed of 16 peptides of 15 - to 18 -mers overlapping by ten residues the preproinsulin 2 sequence and control ovalbumin peptide 323-339 (Table 1).

$T$ cell recognition of preproinsulin 2 peptides. Immunogenicity of preproinsulin 1 peptides was tested by subcutaneous immunization of individual NOD mice with $50 \mu \mathrm{g}$ of peptide emulsified in CFA (Sigma-Aldrich) as previously described (26). Spleen cells were obtained 10 days after immunization and tested for their capacity to respond to the immunizing peptide by incubation with peptide-pulsed APCs. Irradiated (20 Gy) NOD spleen cells obtained from naive 8-week-old female mice, preincubated for 2 hours with $20 \mu \mathrm{g} / \mathrm{ml}$ peptide, were used as APCs. Spleen cells from each individual mouse were tested in triplicate against the 16 proinsulin peptides used for immunization. Cultures were maintained in DMEM complemented by $10 \%$ FCS, 20 $\mathrm{mM}$ HEPES, $1 \mathrm{mM}$ sodium pyruvate, $100 \mathrm{IU} / \mathrm{ml}$ penicillin, $100 \mathrm{IU} / \mathrm{ml}$ streptomycin, $50 \mu \mathrm{M} \beta$-mercaptoethanol, and $2 \mathrm{mM}$ L-glutamine (Gibco Invitrogen Corporation, Cergy Pontoise, France). The response to peptides was assessed by IL-2 production as detected by proliferation of the IL-2-dependent cell line (CTLL-2). Proliferation was evaluated by thymidine incorporation. Results are expressed as mean cpm of triplicate wells in the presence of tested or control peptide.

Statistical analysis. Statistical analyses were performed using log-rank and $\chi$-square tests.

\section{Results}

Characterization of Ins2 $2^{+-}$and Ins2 $2^{-/-}$mice. Heterozygote carriers of the proinsulin 2-deficient allele were genotyped by PCR for diabetes susceptibility markers at each backcross generation. At $\mathrm{BC} 2$, four diabetes susceptibility genes were fixed, including Idd1. At BC4, 16 susceptibility genes were fixed (Idd1 to Idd16). Ins $2^{+/-}$ mice resulting from $\mathrm{BC} 4$ were intercrossed. Genotyping of BC4 intercross mice yielded the expected Ins $2^{-/-}$, Ins $2^{+/-}$, and Ins $2^{+/+}$progeny (Figure 1a). To control the transfer of the deficient proinsulin 2 allele, proinsulin 1 and proinsulin 2 RNAs were examined. Proinsulin 1 RNA was detected in the pancreas of all animals studied (Ins2 $2^{-/-}$, Ins2 ${ }^{+/-}$, and Ins2 $2^{+/+}$mice) (data not shown). Proinsulin 2 RNA was detected in thymus and islets of Ins $2^{+/+}$and Ins2 ${ }^{+/-}$mice but not of Ins2 $2^{-/-}$mice (Figure 1b). Finally, we verified that intercross female and male mice carried the NOD D7Mit191, D7Mit308, and D7Mit232 markers, excluding a role in our model of a 22 -cM region in which a C57BL/6 gene has been previously shown to accelerate diabetes (28). As previously reported in proinsulin 2-deficient 129 mice (28), there was no difference among Ins2 $2^{+/}$, Ins2 $2^{+/-}$, and Ins2-/NOD mice in weight, glycemia, and insulinemia at 4 weeks of age (data not shown).

Incidence of diabetes and insulitis in proinsulin 2-deficient mice. Analysis of progeny resulting from $\mathrm{BC} 4$ intercross showed a significant acceleration of diabetes onset in both male and female mice. Seventy-seven percent of female and $28 \%$ of male Ins $2^{+/+}$mice became diabetic by 27 weeks of age. By contrast, $100 \%$ of Ins $2^{-/-}$mice became diabetic by 15 weeks of age in the case of females and by 21 weeks of age in the case of males (Figure 2). Diabetes onset occurred earlier in Ins2-/- than in Ins $2^{+/+}$mice. The first Ins $2^{-/-}$mice that developed diabetes were 9 weeks old, as compared with 13 weeks of age in the case of Ins2 $2^{+/+}$mice (Figure 2). In Ins2-/- mice, diabetes onset occurred earlier in females than in males. Onset spanned from 9 to 15 weeks of age in female mice and from 12 to 21 weeks in male mice. Finally, there was no significant increase in the incidence of diabetes or acceleration of diabetes onset in Ins $2^{+/-}$heterozygotes as compared with Ins $2^{+/+}$mice. These results suggest that the lack of proinsulin 2 expression leads to an accelerated form of diabetes, while the decrease in expression in heterozygotes has no consequence for the appearance of hyperglycemia.

Pancreata obtained from 8 -week-old Ins $2^{-/}$mice showed extensive islet infiltration, contrasting with pancreata from Ins $2^{+/+}$mice, in which only a minority of islets were infiltrated (Figure 3). Three of five female Ins $2^{-/}$mice showed insulitis in more than $50 \%$ of islets at 8 weeks of age. By contrast, all female Ins $2^{+/+}$mice showed more than $75 \%$ normal islets at the same age. Only $30 \%$ of islets from female Ins $2^{-/-}$mice were free of insulitis (Figure 3). All Ins2 ${ }^{--}$male mice at 8 weeks of age had more than $75 \%$ normal islets. In Ins $2^{+/-}$female mice, insulitis was comparable to that seen in Ins2 $2^{-/-}$mice (Figure 3), indicating a striking difference in the extent of insulitis as compared with Ins $2^{+/+}$mice despite the absence of increased incidence of spontaneous diabetes.

\section{Table 1}

Preproinsulin 2 peptide library

$\begin{array}{lc}\text { Peptides } & \text { Sequences } \\ 2(1-15) & \text { MALWMRFLPLLALLF } \\ 2(7-23) & \text { FLPLLALLFLWESHPTQ } \\ 2(14-30) & \text { LFLWESHPTQAFVKQHL } \\ 2(20-35) & \text { HPTQAFVKQHLCGSHL } \\ 2(26-41) & \text { VKQHLCGSHLVEALYL } \\ 2(33-47) & \text { SHLVEALYLVCGERG } \\ 2(40-56) & \text { YLVCGERGFFYTPMSRR } \\ 2(46-60 & \text { RGFFTPMSRREVED } \\ 2(50-65) & \text { YTPMSRREVEDPQVAQ } \\ 2(56-71) & \text { REVEDPQVAQLELGGG } \\ 2(61-78) & \text { PQVAQLELGGGPGAGDLQ } \\ 2(66-83) & \text { LELGGGPGAGDLQTLALE } \\ 2(71-88) & \text { GPGAGDLQTLALEVAQQK } \\ 2(79-94) & \text { TLALEVAQQKRGIVDQ } \\ 2(88-103) & \text { KRGIVDQCCTSICSLY } \\ 2(93-110) & \text { DQCCTSICSLYQLENYCN }\end{array}$




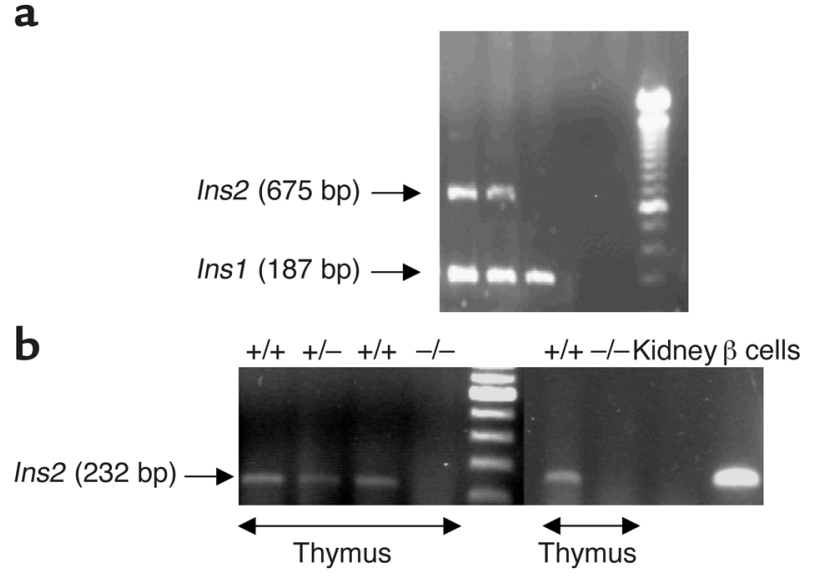

Figure 1

Genotyping of intercross mice for the gene (a) and RT-PCR analysis of proinsulin 2 gene expression (b). (a) A 675-bp PCR fragment corresponding to proinsulin 2 (Ins2) was observed in Ins $2^{+/+}$and Ins $2^{+/-}$ mice. All mice expressed a 187-bp PCR fragment corresponding to the proinsulin 1 gene (Ins1). (b) Amplification of transcripts for proinsulin 2 using total thymic RNA from Ins $2^{+/+}, \operatorname{lns} 2^{+/-}$, and Ins2 $2^{-/-}$mice. Total kidney RNA and islet RNA from Ins $2^{+/+}$mice were used, respectively, as negative and positive controls. A 232-bp fragment was obtained by PCR in Ins $2^{+/+}$and Ins2 $2^{+/-}$mice.

In order to eliminate the possibility that the reduced capacity to produce insulin contributed to the acceleration of disease in Ins $2^{-/-}$mice, Ins2-/- and Ins2 $2^{+/} 129$ mice were evaluated for fasting glycemia and insuline$\mathrm{mia}$, and for glycemia following an intraperitoneal glucose load. No significant difference was observed between the two lines. Glycemia and insulin levels were $138 \pm 30 \mathrm{mg} / \mathrm{dl}$ and $371 \pm 53 \mathrm{pg} / \mathrm{ml}$, respectively, in Ins2 ${ }^{-/}$mice, and $120 \pm 27 \mathrm{mg} / \mathrm{dl}$ and $374 \pm 76 \mathrm{pg} / \mathrm{ml}$, respectively, in Ins2 $2^{+/+}$mice in the fasting state. Sixty and 120 minutes after a $2-\mathrm{g} / \mathrm{kg}$ glucose load, glycemia levels were $212 \pm 81 \mathrm{mg} / \mathrm{dl}$ and $160 \pm 7 \mathrm{mg} / \mathrm{dl}$, respectively, in Ins $2^{-/-}$mice, and $223 \pm 47 \mathrm{mg} / \mathrm{dl}$ and $144 \pm 26 \mathrm{mg} / \mathrm{dl}$, respectively, in Ins $2^{+/+}$mice. Taken together with a previous report indicating that pancreatic insulin contents were comparable in wild-type and proinsulin 2-deficient 129 mice (28), these data suggest that accelerated development of diabetes is not dependent on $\beta$ cell function.

Transfer of diabetes by spleen cells from proinsulin 2-deficient mice. Increased incidence of diabetes in Ins $2^{-/-}$mice and increased insulitis in Ins2 $2^{-/-}$and Ins2 $2^{+-}$mice show that introduction of a null proinsulin 2 gene mutation on the NOD background leads to an accelerated form of

\footnotetext{
Figure 2

Incidence of diabetes in BC4 intercross progeny. The number of Ins $2^{+/+}$(filled diamonds), Ins $2^{+/-}$(open squares), and Ins2-/- (filled circles) mice was respectively 9,14 , and 5 among female mice (a) and 7,14 , and 3 among male mice (b). Significant differences were seen between Ins $2^{+/+}$and Ins $2^{-/-}$mice $(P<0.001$ and $P<0.05$, respectively, in female and male mice) and between Ins $2^{-/-}$and Ins $2^{+/-}$mice $(P<0.001$ and $P<0.01$, respectively, in female and male mice), but not between Ins $2^{+/-}$and Ins2 $2^{+/+}$mice.
}

diabetes. In order to determine whether this relates to increased diabetogenic potential of $\mathrm{T}$ cells in proinsulin 2-deficient mice, we performed transfer experiments by injecting spleen cells from control or proinsulin-deficient mice into NOD-scid recipients. Spleen cells from 8week-old female conventional NOD mice show a low capacity to transfer diabetes into NOD-scid recipients. In the present experiments, spleen cells from 8-week-old Ins $2^{+/+}$mice transferred diabetes in only $20 \%$ of NODscid recipients (Figure 4). By contrast, spleen cells from female Ins2 $-/$ mice transferred diabetes in $82 \%$ of NODscid recipients by 100 days after transfer $\left(P<0.04\right.$, Ins $2^{+/+}$ vs. Ins $2^{+/+}$female donors). Transfer efficacy was $100 \%$ when spleen cells from diabetic donors were injected into the NOD-scid recipients. Spleen cells from 8-week-old Ins $2^{-/-}$male or Ins $2^{+/-}$female donors showed no increase in their capacity to transfer diabetes as compared with Ins $2^{+/+}$female donors.

Anti-insulin and anti-GAD autoantibodies in proinsulin 2deficient mice. Acceleration of diabetes in Ins2 $2^{-/}$mice was hypothesized to relate to silencing of a key autoantigen in the development of anti- $\beta$ cell autoimmunity. IAAs detected at 8 weeks of age in prediabetic NOD mice have been suggested to correlate with diabetes susceptibility (5). To evaluate whether specific recognition of insulin was altered in Ins2 $2^{-/}$mice, sera were analyzed for the presence of IAAs. Striking differences in the prevalence of IAAs were seen among Ins2-/-, Ins $2^{+/-}$, and Ins2-/- NOD mice. Altered recognition of insulin was an early defect in proinsulin 2-deficient mice. At 4 weeks of age, no female Ins $2^{+/+}$NOD

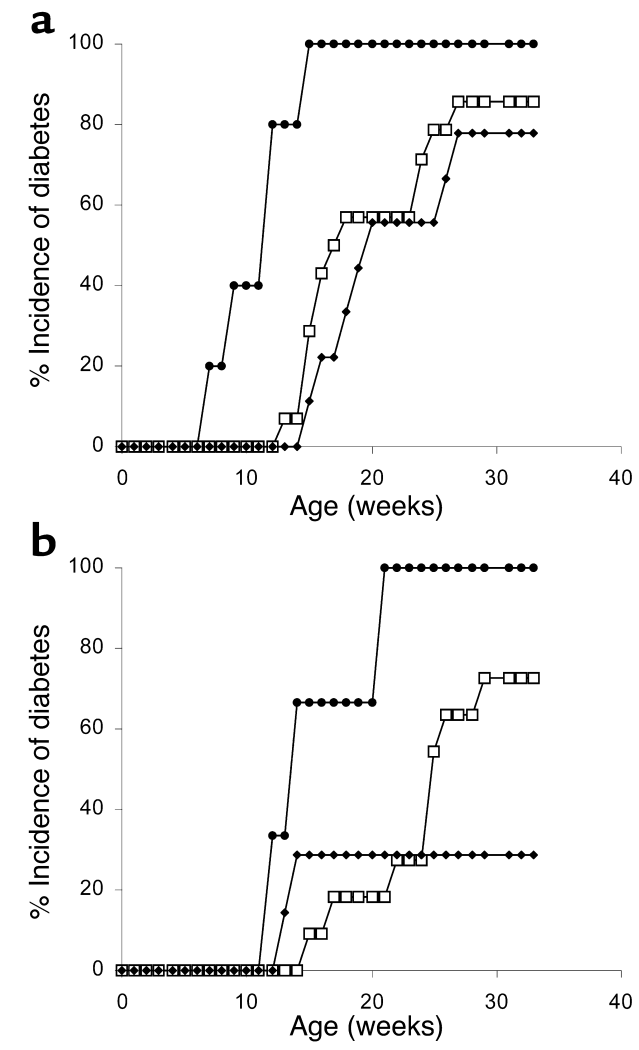




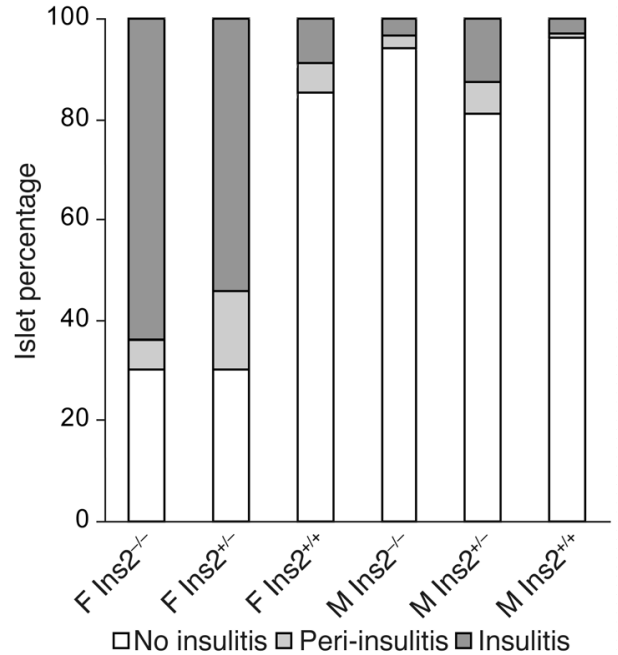

Figure 3

Insulitis in 8-week-old Ins $2^{+/+}, \operatorname{Ins} 2^{+/-}$, and Ins $2^{-/-}$mice. Three pancreatic sections were obtained from each individual mouse (five mice per group). A mean of 32 islets for each group was scored. $F$, female; $M$, male.

mice were positive for IAAs as compared with $47 \%$ of Ins $2^{-/-}(P=0.0007)$ and $60 \%$ of Ins $2^{+/-}$mice $(P=0.0001)$. Among males, $25 \%$ of Ins $2^{-/-}$and $20 \%$ of Ins $2^{+-}$mice, but only $7 \%$ of Ins $2^{+/+}$mice, were positive (Figure $5 \mathrm{a}$ ). At 8 weeks of age, $82 \%$ of female Ins2-- NOD mice possessed IAAs as compared with $50 \%$ of Ins $2^{+} /-(P<0.055)$ and $40 \%$ of Ins $2^{+/+}$NOD mice $(P<0.007)$ (Figure $5 b$ ). Among male mice, the prevalence of IAAs was higher in Ins2 $2^{-/-}$than in Ins2 $2^{+/+}$mice, although the difference was not statistically significant (data not shown).

The possibility that increased prevalence of IAAs was secondary to accelerated destruction of $\beta$ cells rather than directly related to altered recognition of insulin in Ins $2^{+/+}$mice had not, however, been excluded. To address this issue, we evaluated proinsulin 2-deficient mice for the presence of autoantibodies to a control $\beta$ cell autoantigen and for the prevalence of sialitis. As shown in Figure $5 c$, all mice were positive for anti-GAD autoantibodies. No difference in the prevalence of anti-GAD autoantibodies among Ins2-/-, Ins2 $2^{+-}$, and Ins2 $2^{+/+}$mice was seen at 4 and 8 weeks of age. Likewise, extent of sialitis at 12 weeks of age was comparable in Ins2 $2^{-/}$and Ins $2^{+/+}$mice. The number of mice with sialitis was four of four, eight of nine, and five of six in Ins2 $2^{+/}, \mathrm{Ins}^{+/-}$, and Ins2 $2^{-/}$mice, respectively. The mean infiltrate surface was $2.63 \% \pm 0.80 \%, 2.2 \% \pm 0.79 \%$, and $2.07 \% \pm 0.82 \%$ and the mean number of mononuclear cell infiltrates was $1.31 \pm 0.18,0.78 \pm 0.17$, and $0.90 \pm 0.25$ in Ins2 ${ }^{+/+}$, Ins $2^{+/-}$, and Ins2 ${ }^{--}$mice, respectively.

The proinsulin-specific Tcell repertoire in Ins $2^{-/-}$and Ins $2^{+/+}$ mice. Since proinsulin 2-deficient mice showed accelerated insulitis and diabetes, increased capacity to transfer diabetes, and increased immune response to insulin, we asked whether the absence of proinsulin expression in the thymus could imprint an altered $\mathrm{T}$ cell repertoire in the periphery. In order to characterize the repertoire of
T cells specific for proinsulin 2 in proinsulin 2-deficient and wild-type mice, we immunized Ins $2^{-/-}$and Ins2 $2^{+/}$ mice against each of the 16 proinsulin 2 peptides defined in Table 1. Both Ins $2^{-/-}$and Ins2 $2^{+/+}$mice showed a significant $\mathrm{T}$ cell response, with IL-2 secretion, to proinsulin 2 peptides $14-30,20-35,33-47$, and 71-88 (Figure 6). Most interestingly, however, Ins2 ${ }^{-/-}$mice further showed a significant IL-2 response against proinsulin 2 peptide 88-103. As previously reported in the conventional NOD strain (26), no response to peptide 88-103 was observed in Ins2 $2^{+/+}$mice, suggesting that expression of proinsulin 2 in wild-type mice imprinted the silencing of peptide 88-103-specific T cells. Interestingly, proinsulin 2 peptide $88-103$ corresponds to a shared sequence between proinsulin 2 and proinsulin 1 .

\section{Discussion}

Proinsulin 2 has been reported as the major proinsulin isoform that is recognized during the autoimmune reaction to $\beta$ cells in the NOD mouse (8-12). A majority of $\mathrm{CD}^{+} \mathrm{T}$ cell clones generated in vitro from islet infiltrates recognize insulin 2 peptide B9-23 (8) and accelerate diabetes development when injected into young NOD recipients (9). The expression of two proinsulin isoforms in the mouse allowed us to introduce a null proinsulin 2 mutation on the NOD background and evaluate its consequences for the development of autoimmunity in the absence of significant metabolic disturbance. An increase in proinsulin 1 gene expression has been shown to compensate for proinsulin 2 knockout in $129 / \mathrm{Sv}$ mice (17) and is expected to maintain normoglycemia and normal insulin levels prior to the development of autoimmunity to $\beta$ cells in the NOD mouse (29). We observed accelerated diabetes development in Ins2 ${ }^{--}$NOD mice. Extensive insulitis developed in both Ins2 $2^{--}$and Ins $2^{+/-}$mice. Importantly, all phenotyped

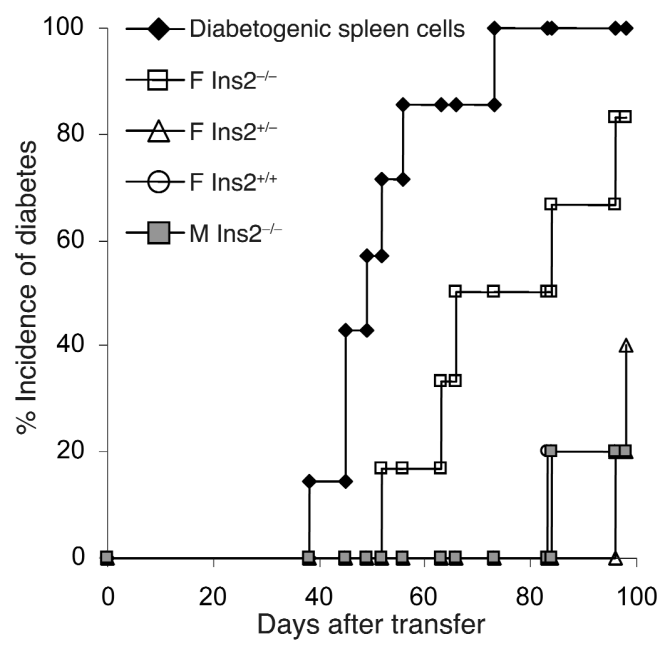

\section{Figure 4}

Transfer of spleen cells from 8-week-old proinsulin 2-deficient and control NOD mice in NOD-scid recipients. Spleen cells were pooled from five donors in each group. Diabetogenic spleen cells were used as positive control. Five recipient mice were used in each group. $F$, female NOD donors; M, male NOD donors. 
a

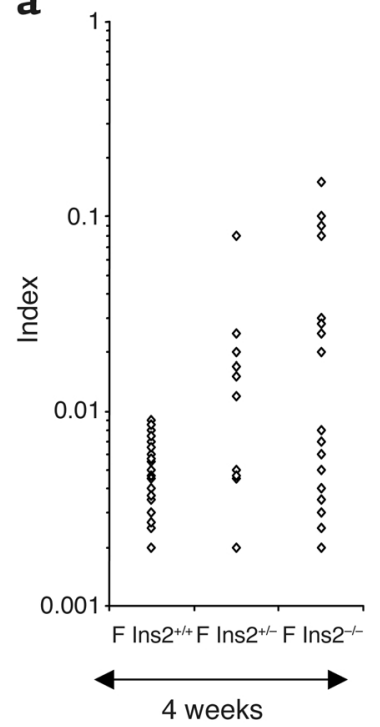

b

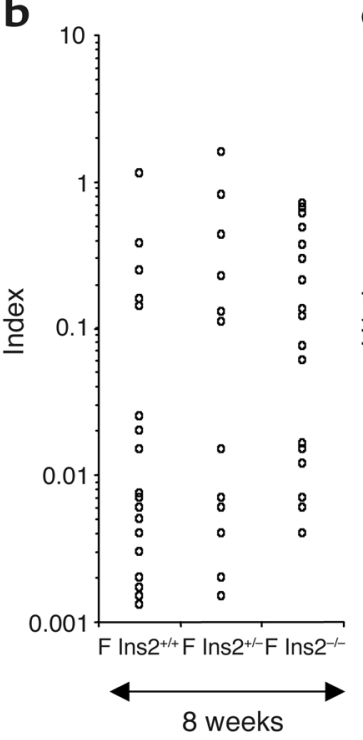

c

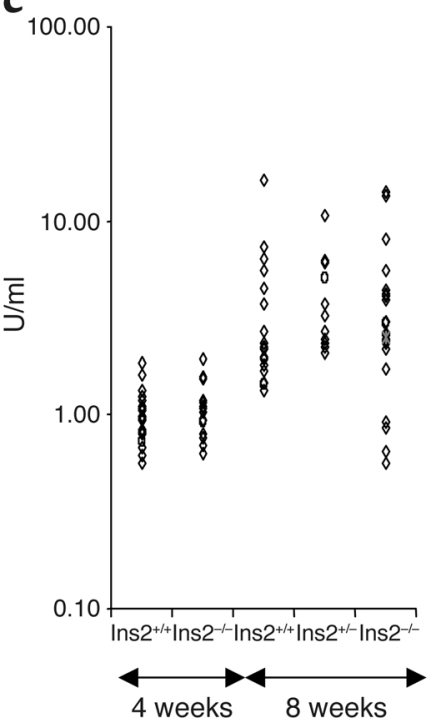

Figure 5

Autoantibodies in proinsulin 2-deficient NOD mice. Serum samples from 4-week-old (a and $\mathbf{c}$ ) and 8-week-old (b and c) female ( $\mathrm{F}$ ) Ins $2^{+/+}, \operatorname{Ins} 2^{+/-}$, and Ins $2^{-/-}$mice were analyzed. (a and b) IAAs. (c) GAD autoantibodies.

mice carried NOD alleles within a 22-cM chromosome 7 plateau in which a C57BL/ 6 gene has been reported to accelerate diabetes (28), indicating that the role of this non-NOD gene was excluded in Ins2 $2^{--}$mice. There is no evidence that insulitis extent was increased at 8 weeks of age, even though diabetes development was accelerated in male Ins $2^{-/-}$mice. This does not exclude, however, the possibility that proinsulin 2-deficient males developed accelerated insulitis at a later age. Accelerated activation of T cells against $\beta$ cells was evidenced by increased transfer of diabetes by spleen cells from young Ins2 $2^{-/-}$mice. Acceleration of diabetes in Ins $2^{-/-}$mice was hypothesized to relate to either altered immune response to proinsulin or nonspecific acceleration of autoimmunity independently of proinsulin. Our data favor the first hypothesis. Anti-GAD autoantibodies and IAAs have been detected during the disease process in the NOD mouse (2). IAAs detected at 8 weeks of age have further been shown to strongly associate with the development of diabetes (5). IAA levels were increased in Ins $2^{-1-}$ mice, while the prevalence of autoantibodies to $\mathrm{GAD}$ was comparable in Ins $2^{-/-}$and Ins2 $2^{+/+}$mice. The prevalence of sialitis was also comparable in Ins2 $2^{-/}$ and Ins $2^{+/+}$mice. It is thus likely that deficient expression of proinsulin 2 led to proinsulin-specific acceleration

\section{Figure 6}

T cell response of wild-type (a) and Ins2-/- (b) NOD mice to proinsulin 2 peptides. Each individual mouse was immunized against one single peptide of the proinsulin 2 peptide library described in Table 1 , in CFA. Spleen cells were tested against the peptide used for immunization, and ovalbumin peptide $323-339$ as control. IL-2 was evaluated in supernatants as described in Methods. Each histogram represents the mean \pm SD of triplicate wells, expressed in cpm. of autoimmunity to $\beta$ cells rather than a nonspecific defect of immune tolerance.

Our present data give evidence that expression of proinsulin 2 is not a prerequisite for development of autoimmunity to $\beta$ cells in the NOD mouse. The detection of IAAs in Ins2-/- NOD mice also confirms that proinsulin 1 is an autoantigen in this model. Using a series of overlapping preproinsulin peptides in a systematic approach to characterize proinsulin epitopes recognized by $\mathrm{CD} 4^{+} \mathrm{T}$ cells in the NOD mouse, we previously identified $\mathrm{T}$ cells specific for epitopes located on both preproinsulin 1 and preproinsulin 2 (26). In the human, proinsulin epitopes distinct from $B$ chain peptides are recognized by $\mathrm{CD} 4^{+} \mathrm{T}$ cells, including epitopes located within the $\mathrm{C}$ peptide region $(6,30)$.

Increased immune recognition of proinsulin and acceleration of diabetes in Ins2 $2^{-/-}$mice possibly relate to several mechanisms. A first possibility is that proinsulin 2 epitopes specifically activate regulatory $\mathrm{T}$ cells. This hypothesis fits with previous reports pointing to the protection induced by administration of insulin B chain peptide 9-23 in nondiabetic NOD mice (10-12). However, the demonstration that regulatory $\mathrm{T}$ cells specifically

a

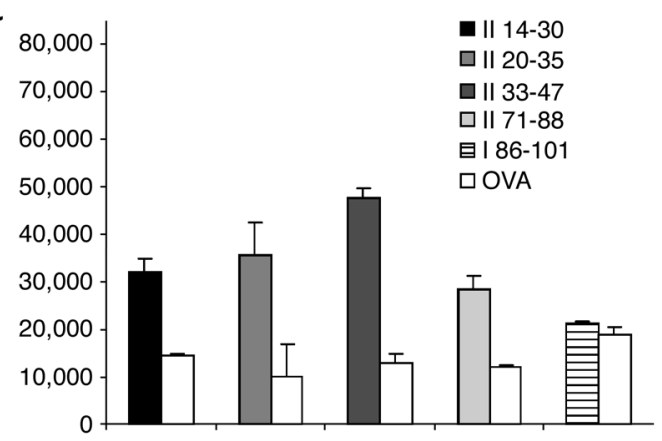

b

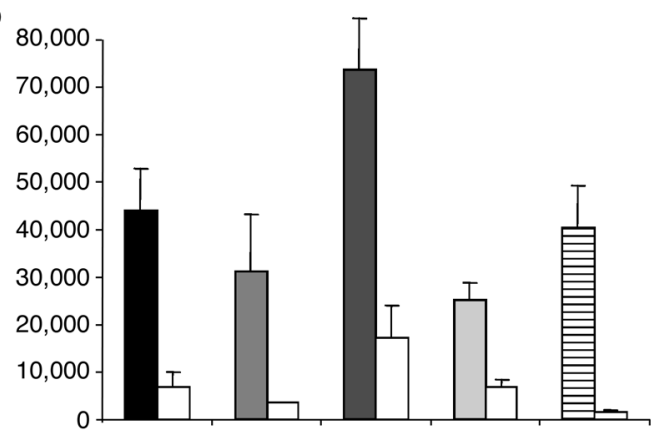


recognize peptide 9-23 is missing, and antigen specificity of regulatory $\mathrm{T}$ cells remains elusive in most models. An alternative hypothesis is that proinsulin 2 operates by controlling the peripheral $\mathrm{T}$ cell repertoire, as in experimental allergic encephalomyelitis (31). Proinsulin 2 is expressed within the thymus (18-21). The importance of proinsulin expression in the thymus is strengthened by data showing that allelic variation of proinsulin expression influences the risk for type 1 diabetes in the human (14-16) and that insulin expression in the thymus modulates $T$ cell tolerance to insulin in the mouse (20). The role of thymic expression of viral antigens in the mouse has further been shown to control both the frequency of specific $\mathrm{T}$ cell precursors and the severity of diabetes in transgenic mice expressing lymphochoriomeningitis proteins in $\beta$ cells (32). To address whether expression of proinsulin 2 modulates the repertoire of insulin-specific $T$ cells in our model, we used a series of overlapping preproinsulin 2 peptides in a systematic approach to characterize epitopes recognized by $\mathrm{CD} 4^{+} \mathrm{T}$ cells in wild-type and Ins2 $2^{--}$mice. In addition to four peptides that were recognized by peripheral $\mathrm{T}$ cells from both wild-type and Ins $2^{-/-}$mice, Ins $2^{-/-}$mice showed a response to peptide 88-103. Wild-type mice showed no response to peptide 88-103, giving evidence that $\mathrm{T}$ cell precursors specific for peptide 88-103 are eliminated or silenced in mice expressing proinsulin 2. Interestingly, peptide $88-103$ is mostly located in insulin A chain and is common to proinsulin 2 and proinsulin 1 , which is the only isoform expressed in Ins2-/- mice. Peripheral 88-103-specific T cells are thus likely to contribute to acceleration of diabetes development in Ins2 $2^{-/}$mice.

In conclusion, the observation that NOD mice that are deficient for proinsulin 2 expression both within $\beta$ cells and within the thymus develop accelerated diabetes points to the importance of proinsulin as an autoantigen in the NOD mouse. There is strong evidence in the human that VNTR alleles flanking the insulin gene are key determinants of diabetes susceptibility. They may control the $\beta$ cell response to glucose within the islets of Langerhans and the expression of proinsulin in the thymus (14-16). In the mouse, there is no allelic variability in the $5^{\prime}$ VNTR flanking the insulin gene. Ins2-/- NOD mice may thus represent a new model that will allow study of the role of thymic expression of insulin in susceptibility to type 1 diabetes.

\section{Acknowledgments}

This work was supported by Juvenile Diabetes Foundation International grant 1-2001-751 and by Action Concertée Incitative Biologie du Développement et Physiologie Intégrative 2000 no. 42. We thank Chantal Lotton for performing IAA assays.

1. Atkinson, M.A., and Maclaren, N.K. 1993. Islet cell autoantigens in insulin-dependent diabetes. J. Clin. Invest. 92:1608-1616.

2. Tisch, R., et al. 1993. Immune response to glutamic acid decarboxylase correlates with insulitis in non-obese diabetic mice. Nature. 366:72-75.

3. Palmer, J.P., et al. 1983. Insulin antibodies in insulin-dependent diabetics before insulin treatment. Science. 222:1337-1339.

4. Kuglin, B., Gries, F.A., and Kolb, H. 1988. Evidence of IgG autoantibodies against human proinsulin in patients with IDDM before insulin treatment. Diabetes. 37:130-132.

5. Yu, L., et al. 2000. Early expression of antiinsulin autoantibodies of humans and the NOD mouse: evidence for early determination of subsequent diabetes. Proc. Natl. Acad. Sci. U. S. A. 97:1701-1706.

6. Dubois-Laforgue, D., Carel, J.C., Bougneres, P.F., Guillet, J.G., and Boitard, C. 1999. T-cell response to proinsulin and insulin in type 1 and pretype 1 diabetes. J. Clin. Immunol. 19:127-134.

7. Ziegler, A.G., Hummel, M., Schenker, M., and Bonifacio, E. 1999. Autoantibody appearance and risk for development of childhood diabetes in offspring of parents with type 1 diabetes. Diabetes. 48:460-468.

8. Wegmann, D.R., Norbury-Glaser, M., and Daniel, D. 1994. Insulin-specific T cells are a predominant component of islet infiltrates in pre-diabetic NOD mice. Eur. J. Immunol. 24:1853-1857.

9. Daniel, D., Gill, R.G., Schloot, N., and Wegmann, D. 1995. Epitope specificity, cytokine production profile and diabetogenic activity of insulin-specific T cell clones isolated from NOD mice. Eur. J. Immunol. 25:1056-1062.

10. Muir, A., et al. 1995. Insulin immunization of nonobese diabetic mice induces a protective insulitis characterized by diminished intraislet interferon-gamma transcription. J. Clin. Invest. 95:628-634.

11. Daniel, D., and Wegmann, D.R. 1996. Protection of nonobese diabetic mice from diabetes by intranasal or subcutaneous administration of insulin peptide B-(9-23). Proc. Natl. Acad. Sci. U. S. A. 93:956-960.

12. Hutchings, P., and Cooke, A. 1998. Protection from insulin dependent diabetes mellitus afforded by insulin antigens in incomplete Freund's adjuvant depends on route of administration. J. Autoimmun. 11:127-130.

13. Wong, F.S., et al. 1999. Identification of an MHC class I-restricted autoantigen in type 1 diabetes by screening an organ-specific cDNA library. Nat. Med. 5:1026-1031.

14. Lucassen, A.M., et al. 1993. Susceptibility to insulin dependent diabetes mellitus maps to a $4.1 \mathrm{~kb}$ segment of DNA spanning the insulin gene and associated VNTR. Nat. Genet. 4:305-310.

15. Pugliese, A., et al. 1997. The insulin gene is transcribed in the human thymus and transcription levels correlated with allelic variation at the INS VNTRIDDM2 susceptibility locus for type 1 diabetes. Nat. Genet. 15:293-297.

16. Vafiadis, P., et al. 1997. Insulin expression in human thymus is modulated by INS VNTR alleles at the IDDM2 locus. Nat. Genet. 15:289-292.

17. Duvillie, B., et al. 1997. Phenotypic alterations in insulin-deficient mutant mice. Proc. Natl. Acad. Sci. U. S. A. 94:5137-5140.

18. Deltour, L., et al. 1993. Differential expression of the two nonallelic proinsulin genes in the developing mouse embryo. Proc. Natl. Acad. Sci. U. S. A. 90:527-531.

19. Throsby, M., et al. 1998. Pancreatic hormone expression in the murine thymus: localization in dendritic cells and macrophages. Endocrinology. 139:2399-2406.

20. Serreze, D.V., and Leiter, E.H. 1994. Genetic and pathogenic basis of autoimmune diabetes in NOD mice. Curr. Opin. Immunol. 6:900-906.

21. Derbinski, J., Schulte, A., Kyewski, B., and Klein, L. 2001. Promiscuous gene expression in medullary thymic epithelial cells mirrors the peripheral self. Nat. Immunol. 2:1032-1039.

22. Chentoufi, A.A., and Polychronakos, C. 2002. Insulin expression levels in the thymus modulate insulin-specific autoreactive T-cell tolerance. Diabetes. 51:1383-1390.

23. Vigneau-Hermellin, M., et al. 1997. Rejection of islets differing by a single antigen is dependent on donor MHC. Diabetes. 46:765-769.

24. Larger, E., Becourt, C., Bach, J.F., and Boitard, C. 1995. Pancreatic islet beta cells drive $\mathrm{T}$ cell-immune responses in the nonobese diabetic mouse model. J. Exp. Med. 181:1635-1642.

25. Laloux, V., Beaudoin, L., Jeske, D., Carnaud, C., and Lehuen, A. 2001. NK $\mathrm{T}$ cell-induced protection against diabetes in valpha14-jalpha281 transgenic nonobese diabetic mice is associated with a Th2 shift circumscribed regionally to the islets and functionally to islet autoantigen. J. Immunol. 166:3749-3756.

26. Halbout, P., Briand, J.-P., Bécourt, C., Muller, S., and Boitard, C. 2002. T cell response to proinsulin I and II in the NOD mouse. J. Immunol. 169:2436-2443.

27. Neimark, J., and Briand, J.P. 1993. Development of a fully automated multichannel peptide synthesizer with integrated TFA cleavage capability. Pept. Res. 6:219-228.

28. Gonzalez, A., et al. 1997. Genetic control of diabetes progression. Immunity. 7:873-883.

29. Leroux, L., et al. 2001. Compensatory responses in mice carrying a null mutation for Ins1 or Ins2. Diabetes. 50(Suppl. 1):S150-S153.

30. Congia, M., Patel, S., Cope, A.P., De Virgiliis, S., and Sonderstrup, G. 1998. T cell epitopes of insulin defined in HLA-DR4 transgenic mice are derived from preproinsulin and proinsulin. Proc. Natl. Acad. Sci. U. S. A. 95:3833-3838.

31. Huseby, E.S., Sather, B., Husebu, P.G., and Goverman, J. 2001. Agedependent $\mathrm{T}$ cell tolerance and autoimmunity to myelin basic protein. Immunity. 14:471-481.

32. Sevilla, N., et al. 2000. Virus-induced diabetes in a transgenic model: role of cross-reacting viruses and quantitation of effector $\mathrm{T}$ cells needed to cause disease. J. Virol. 74:3284-3292. 